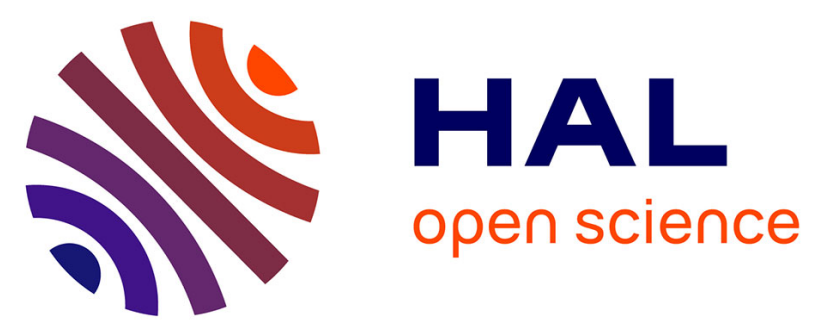

\title{
Photoinduced Cross-Linking of Dynamic Poly(disulfide) Films via Thiol Oxidative Coupling
}

Noémi A Feillée, Abraham Chemtob, Christian Ley, Céline Croutxe-Barghorn, Xavier Allonas, Arnaud Ponche, Didier Le Nouen, Hicham Majjad, Leandro Jacomine

\section{To cite this version:}

Noémi A Feillée, Abraham Chemtob, Christian Ley, Céline Croutxe-Barghorn, Xavier Allonas, et al.. Photoinduced Cross-Linking of Dynamic Poly(disulfide) Films via Thiol Oxidative Coupling. Macromolecular Rapid Communications, 2016, 37 (2), pp.155-160. 10.1002/marc.201500459 . hal02442175

\section{HAL Id: hal-02442175 \\ https://hal.science/hal-02442175}

Submitted on 16 Jan 2020

HAL is a multi-disciplinary open access archive for the deposit and dissemination of scientific research documents, whether they are published or not. The documents may come from teaching and research institutions in France or abroad, or from public or private research centers.
L'archive ouverte pluridisciplinaire HAL, est destinée au dépôt et à la diffusion de documents scientifiques de niveau recherche, publiés ou non, émanant des établissements d'enseignement et de recherche français ou étrangers, des laboratoires publics ou privés. 
DOI: $10.1002 / m a r c$

Article Type: Communication

Photoinduced Cross-linking of Dynamic Poly(disulfide) Films via Thiol Oxidative Coupling ${ }^{1}$

Noémi Feillée, Abraham Chemtob,* Christian Ley,* Céline Croutxé-Barghorn, Xavier Allonas, Arnaud Ponche, Didier Le Nouen, Hicham Majjad, Léandro Jacomine

N. Feillée, Dr. A. Chemtob, Prof. C. Ley, Prof. Croutxé-Barghorn, Prof. X Allonas

Laboratory of Macromolecular Photochemistry and Engineering

University of Haute-Alsace

3 rue Alfred Werner, 68093 Mulhouse Cedex, France

E-mail: abraham.chemtob@uha.fr

Dr. A. Ponche

Institute of Mulhouse Material Science, UMR-CNRS 7361

University of Haute-Alsace

3 rue Alfred Werner, 68093 Mulhouse Cedex, France

Dr. D. Le Nouen

Laboratory of Organic and Bioorganic Chemistry

University of Haute-Alsace

3 rue Alfred Werner, 68093 Mulhouse Cedex, France

H. Majjad

Institut de Physique et Chimie des Matériaux de Strasbourg, UMR-CNRS 7504

University of Strasbourg

23 rue du Loess, BP 43, F-67034, Strasbourg Cedex 2, France.

Dr. L. Jacomine

Institut Charles Sadron, University of Strasbourg, CNRS-UPR22

University of Strasbourg

23 rue du Loess, BP 84047, F-67034, Strasbourg Cedex 2, France

\begin{abstract}
Initially developed as an elastomer with an excellent record of barrier and chemical resistance properties, poly(disulfide) has experienced a revival linked to the dynamic nature of the S-S covalent bond. We report a novel photobase-catalyzed oxidative polymerization of multifunctional thiols to poly(disulfide) network. Based solely on air oxidation, the single-
\end{abstract}

\footnotetext{
${ }^{1}$ Supporting Information is available online from the Wiley Online Library or from the author.
} 
step process is triggered by the photodecarboxylation of a xanthone acetic acid liberating a strong bicyclic guanidine base. Starting with a 1- $\mu \mathrm{m}$ thick film based on trithiol poly(ethylene oxide) oligomer, the UV-mediated oxidation of thiols to disulfides occurs in a matter of minutes both selectively i.e. without over-oxidation, and quantitatively as assessed by a range of spectroscopic techniques. Thiolate formation and film thickness determine the reaction rates and yield. Spatial control of the photopolymerization serves to generate robust micropatterns, while the reductive cleavage of S-S bridges allows the recycling of $40 \%$ of the initial thiol groups.

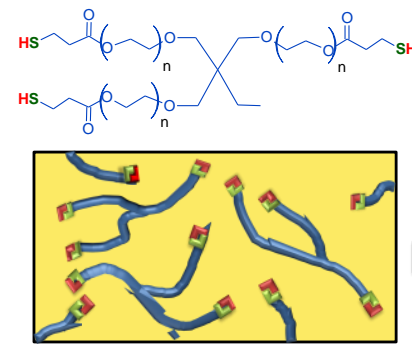

Trithiol oligomer

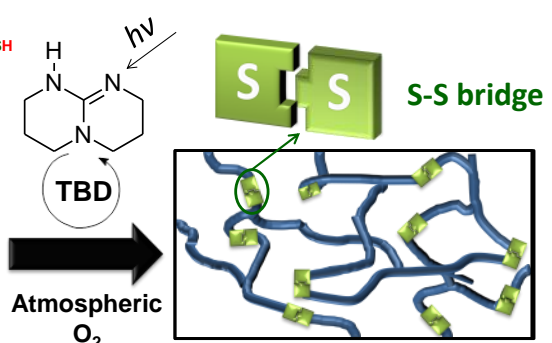

Dynamic covalent poly(disulfide) network 


\section{Introduction}

Once considered a limitation, polymers consisting of repeated reversible covalent bonds such as $\mathrm{C}=\mathrm{N}$ bonds in imine or $\mathrm{C}-\mathrm{O}$ bonds in alkoxyamine — are now highly praised for their adaptability and compositional diversity. ${ }^{[1]}$ Chemists progressively realized that such dynamic polymers able to reorganize structure and constitution on demand provides an avenue for smart stimulus-responsive materials with advanced properties such as reversible surface functionalization, ${ }^{[2]}$ recycling, ${ }^{[3]}$ self-repair, ${ }^{[4,5]}$ or stress relaxation. ${ }^{[6]}$ One of the most intriguing and versatile examples of dynamic covalent bonds is the disulfide bond, which controls processes as important as protein folding and rubber vulcanization. ${ }^{[7]}$ The S-S bond reversibility is expressed through a number of pathways - thiol-disulfide exchange, reduction to thiol or metathesis — and using an extensive range of stimuli, e.g redox species, thiol nucleophiles, ${ }^{[8]}$ UV light. ${ }^{[9]}$ Of major importance is the reversible disulfide/thiol Red/Ox couple, which is ubiquitous in living organisms. ${ }^{[10]}$ Poly(disulfide)s are unique polymers because the dynamic character of the repeated S-S bridges does not prevent an excellent record of "static" properties, such as low vapor permeation, high resistance to solvents and environmental degradation. ${ }^{[1]}$ Accordingly, the major developments for sulfur-containing polymers have focused on high-performance industrial sealants, ${ }^{[12]}$ but also gene delivery ${ }^{[13]}$ through reductive depolymerization. Nevertheless, this unique combination of dynamic and static properties has not garnered so much attention, particularly when considering that the first products were released in the late 1920s. ${ }^{[14]}$

To unlock the full potential of poly(disulfide)s, simple, eco-efficient and industrially scalable processing methods are needed. Three main synthetic routes to disulfide polymers are reported in the literature. ${ }^{[11,14]}$ The first is the heat-induced ring-opening polymerization of cyclic (arylene disulfide) oligomers. ${ }^{[15]}$ The second brings together several polycondensations involving monomers with internal disulfide groups. ${ }^{[16]}$ The third is conceptually the most 
simple because it relies on the base-catalyzed oxidation of multifunctional $(\geq 2)$ thiol derivatives in presence of an oxidizing agent. In contrast to the first two methods, the disulfide bonds are generated in situ, and a broader range of affordable precursors is accessible. ${ }^{[17-19]}$ Industrially, the oxidative coupling of thiol-terminated oligomers is the reference process to cross-link poly(disulfide) rubbers, referred to as Thiokol ${ }^{\circledR}$ or Thioplast ${ }^{[}{ }^{[12]}$ However, this methodology is plagued with several problems, including slow curing, 2-component formulation, toxic (metal) or harmful (organic peroxides) oxidative reagents. The linear polymerization of dithiol monomer solution is even more challenging with insolubility issues, formation of low-molecular-weight products and very long reaction times up to ten hours. ${ }^{[20]}$ Recently, Puskas et al. introduced a more sustainable and effective approach performed in water, thus demonstrating that there is scope for improved processing methods. Using triethylamine catalyst and a pair of oxidants (air and hydrogen peroxide), the oxidative polymerization of ethylene glycol dithiol resulted in a poly(disulfide) precipitate with $\bar{M}_{n}>2.5 \times 10^{5} \mathrm{~g} / \mathrm{mol}^{[21]}$

In this paper, we move forward in describing a fast and single-step light-mediated thiol oxidative polymerization to synthesize disulfide polymer as film. UV control enables the use of storable, ready-to-use, and cost-effective thiol formulations with no pot-life issue. In addition, a simplified and energy-saving photopolymerization procedure is implemented for the first time.

\section{Results and Discussion}

As depicted in Figure 1, our simple procedure starts with the application of a trifunctional poly(ethylene oxide) thiol oligomer $(1300 \mathrm{~g} / \mathrm{mol}, \mathbf{1})$ on a $\mathrm{KBr}$ or glass substrate to form a 1 $\mu \mathrm{m}$-thick liquid film. This latter includes 4 wt. $\%$ of xanthone acetic acid quaternary salt of triazabicyclodecene (TBD) photobase generator (PBG) noted PBG-A, which is commercially available. Recently, Arimitsu et al. proved that this PBG was able to release a strong bicyclic 
guanidine base via a photodecarboxylation reaction with high quantum yield. ${ }^{[22]}$ Herein, subsequent UV irradiation of the photolatent bicomponent 1/PBG-A is performed in air and at ambient temperature with a filtered medium-pressure $\mathrm{Hg}$-Xe lamp $\left(290 \mathrm{~mW} / \mathrm{cm}^{2}, \lambda>330\right.$ $\mathrm{nm}$ ) for $15 \mathrm{~min}$, resulting in a dry film fully insoluble in conventional organic solvents. We present extensive characterization evidence, including Raman and real-time FTIR spectroscopies, XPS, NMR, TGA and DSC, which shows that a quantitative photobasecatalyzed air oxidation of thiol takes place, leading to the formation of a poly(disulfide) network film.

Proof for the formation of disulfide bonds is provided by analyzing the film with Raman spectroscopy at different irradiation times. As shown in Figure 2 (top), the spectrum of $\mathbf{1}(\mathrm{t}=$ 0 min) shows significant differences compared to that of the resulting polymer P1 $(t=15$ min). The gradual decrease of the $v_{\mathrm{S}-\mathrm{H}}$ and $v_{\mathrm{C}-\mathrm{SH}}$ stretching mode features at $2570 \mathrm{~cm}^{-1}$ and $672 \mathrm{~cm}^{-1}$ respectively suggest a thiol consumption induced by UV exposure. After 15 min irradiation, these two characteristic SH signals completely vanish below the noise level. Concomitantly with their decay, we observe in the lower frequency range a large enhancement of the intensity ratio of the S-S stretching mode features at $643 \mathrm{~cm}^{-1}\left(v_{\mathrm{C}-\mathrm{SS}}\right)$ and $510 \mathrm{~cm}^{-1}\left(v_{\mathrm{S}-}\right.$ s). On the basis of these two significant and simultaneous changes (no other modifications is noticeable), it is likely that air oxidation of thiols to disulfide bridges occurs, both selectively i.e. without over-oxidation, and quantitatively (100\% conversion) despite the mobility restriction imposed by the network formation.

To our knowledge, the mild and chemoselective oxidative photopolymerization in air of polythiol is unprecedented. By contrast, the photodissociation in air of monothiol compounds has been previously investigated at shorter wavelength $(\lambda<300 \mathrm{~nm})$, yielding a range of higher oxidation states species such as sulfonic acid, sulfone, thiosulfinate or thiosulfonate. ${ }^{[23,24]}$ By contrast, XPS surface analysis of the $S_{2 p}$ peaks (Fig. S1 of SI) 
conclusively supports the minor role played by these highly oxidized sulfur species, arising at a distinctive higher binding energy than thiols or disulfides. ${ }^{[25]}$

In addition, RT-FTIR spectroscopy was implemented to probe online the film compositional changes throughout the irradiation. The decreasing IR S-H stretching mode feature at $2555 \mathrm{~cm}^{-1}$, shown in the inset plot of Figure 2 (bottom), gives essentially the same information as given by the Raman data, except that rapid scan acquisition provides in this case kinetic details. Thiol conversion-time plot in air (Figure 2, trace a) shows a fast and complete consumption with $90 \%$ conversion accomplished after only 5 min irradiation. In contrast, no conversion was obtained without UV exposure (even after $4 \mathrm{~h}$ ), demonstrating the photolatency of the reactive 1/PBG-A mixture. Additionally, no reaction takes place upon removing the PBG (Figure 2, trace b), which emphasizes the crucial role of thiolates in triggering the oxidation process. To shed further light into the photo-oxidation mechanistic scheme, an experiment was conducted under nitrogen atmosphere (Figure 2, trace c). A strong inhibition is observed in this case, which argues for a prevalent role of atmospheric oxygen in the oxidation process. The air oxidation of thiols to disulfides is a well-established reaction (see Scheme S1 in SI), which has been harnessed to poly(sulfide) synthesis with mixed success. ${ }^{[17]}$ Our hypothesis is that the release of photobase causes the thiol groups to be converted to thiolate. The next step involves electron transfer with oxygen which results in the formation of thiyl radicals and subsequent dimerization to disulfides and step-growth polymerization, as documented by many studies. To complete this concise mechanistic description, two features seem critical for photopolymerization efficiency: (i.) film thickness, and (ii) photocatalyst basicity.

i. Upon increasing gradually the film thickness $(1-10 \mu \mathrm{m})$, slower kinetics and limiting conversion are obtained (Fig. S2-3 of SI). A marked decrease in reactivity is noted above a threshold thickness of $4 \mu \mathrm{m}$, thus indicating an oxygen diffusion limitation effect. In addition, 
at $10 \mu \mathrm{m}$, the final conversion is reduced to $90 \%$ after $15 \mathrm{~min}$ irradiation whereas thinner samples reveal full thiol consumption. Although this result stresses a limitation, it positions this novel UV-curing process as a viable and complementary alternative to radical photopolymerization, in which oxygen inhibition makes the surface polymerization of submicrometer-thick films tricky. ${ }^{[26]}$

ii. The release of base mediates the deprotonation of the trithiol $\mathbf{1}\left(\mathrm{pK}_{\mathrm{a}}=9.87\right.$ in water at $25 \mathrm{C}) .{ }^{[27]}$ The importance of basicity is evidenced by substituting TBD $\left(\mathrm{pK}_{\mathrm{a}}=14.5\right)$ for a less basic $\mathrm{N}$-alkyl morpholine tertiary amine $\left(\mathrm{pK}_{\mathrm{a}}=9.3\right)$ photogenerated with a conventional $\alpha$ aminoketone PBG noted PBG-B (see structure and photolysis mechanism in Scheme S2 of SI). Although quantum yields are different in both species and thus direct comparison difficult, the released tertiary amine led to only $40 \%$ thiol conversion after 15 min irradiation (Figure 2, trace d).

To illustrate the industrial viability of this process, cross-linked films were also produced under a UV-conveyor equipped with a medium-pressure $\mathrm{Hg}$ arc lamp, which is the workhorse equipment for UV-curable coatings. Dry films were obtained after 10 passes $\left(1.35 \mathrm{~J} / \mathrm{cm}^{2}\right.$ per pass) corresponding to an exposure time of only $2.3 \mathrm{~s}$. Raman analysis were consistent with previous results, yielding $95 \%$ conversion of thiol to disulfides (Fig. S4 of SI). Despite the insolubility typical of highly cross-linked polymers, the transparent rubbery film yielded a gel after several days in $\mathrm{CDCl}_{3}$. This allowed its characterization by High Resolution Magic Angle Spinning (HR-MAS) ${ }^{1} \mathrm{H}$ NMR technique. The spectra of $\mathbf{P 1}$ and $\mathbf{1}$ are displayed in Figure 3. The feature at $1.67 \mathrm{ppm}$, straightforwardly attributed to thiol protons $\left(\mathrm{H}_{\mathrm{a}}\right)$ of $\mathbf{1}$, is almost no detectable in P1, thereby confirming the high conversion. In addition, the resonance assigned to methylene protons adjacent to the thiol group at $2.75 \mathrm{ppm}\left(\mathrm{H}_{\mathrm{b}}\right)$ in $\mathbf{1}$ is significantly shifted to $2.92 \mathrm{ppm}\left(\mathrm{H}_{\mathrm{b}}\right.$ ) in the polymer product. These results provide clear evidences that disulfide bonds are created. Note that all these significant results were supported by ${ }^{13} \mathrm{C}$ NMR 
analysis (Fig. S5 of SI). In addition, TGA characterization (Fig. S6 of SI) indicated that the polymer P1 was thermally stable up to $150{ }^{\circ} \mathrm{C}$ under nitrogen atmosphere. Finally, DSC analysis (Fig. S7 of SI) revealed an elastomeric behavior with a glass transition temperature of $-45^{\circ} \mathrm{C}$ fully consistent with the literature data of poly(disulfide). ${ }^{[7]}$

One unique feature of UV-triggered catalyst is to allow spatially-controlled polymerization and surface modification, which are unattainable with a conventional latent catalyst. To demonstrate the photopatterning ability, the 1/PBG-A film was irradiated using a commercial mask aligner equipped with a high-pressure $\mathrm{Hg}$ lamp $\left(14 \mathrm{~mW} / \mathrm{cm}^{2}\right)$. After a UV exposure of 15 min, the solid P1-based film was washed several times with acetone to remove the unreacted or soluble parts. Figure 4 (top) shows two optical microscopy images of the developed film (right) and the original mask (left), indicative of the quality of the micro-scale photolithographic process. In addition, profilometry enabled to obtain a height profile of the pattern (Fig. S8 of SI). Thiol photooxidative polymerization thus represents another chemical amplification reaction for negative tone resist, because a single photon can initiate a cascade of chemical reactions.

A second application made possible thanks to $\mathrm{S}-\mathrm{S}$ bond reversibility is the reductive cleavage of the poly(disulfide) network as a means to recycle the starting thiol oligomer. To this purpose, the powdered product $\mathbf{P 1}$ was stirred in a $\mathrm{CHCl}_{3}$ solution containing 8 equivalents of dithiothreitol and 0.75 eq of triethylamine. Dithiothreitol forms a very stable six-membered ring in its oxidized state, and is currently the most widely used reducing agent of disulfide-based proteins. ${ }^{[8]}$ A gradual solubilisation was noted, and a slightly turbid solution was obtained after 12 days under stirring (see images in Fig. S9 of SI). The reaction progress was assessed using ${ }^{13} \mathrm{C}$ NMR. Figure 4 (down) gives the ${ }^{13} \mathrm{C}$ NMR spectra of $\mathbf{1}, \mathbf{P} \mathbf{1}$ and P1R the polymer after reduction. The extent of reduction is reflected by the integral ratios of the carbon signal of the methylene group $\left(C_{b}\right)$ adjacent to the thiol group at 19.7 ppm to that of a 
reference resonance, such as the $\mathrm{CH}_{2}\left(\mathrm{C}_{\mathrm{j}}\right)$ in alpha position of the methyl group at $22.9 \mathrm{ppm}$. The initial ratio of 2.2 found in precursor 1 is reduced to less than 0.1 ( $5 \%$ of thiol group remaining) after photopolymerization $(\mathbf{P 1})$, then rises back to 0.8 (40\% of thiol group regenerated) at the end of the reduction process (P1R). These data demonstrate a partial regeneration of thiol group despite P1 cross-linked structure. Additionally, control experiments carried out without reductant have confirmed the immunity of the disulfide groups (Fig. S10 of SI).

\section{Conclusion}

In conclusion, we present the first UV-mediated pathway to cross-linked poly(disulfide) films based on thiol air oxidation. Significant advantages compared to previous methods include fast and complete thiol conversion, formation of chemically resistant film, and a onestep process starting from a simple and photolatent "thiol-PBG" formulation. There is no apparent limitation on substrate, and extension to a range of thiol oligomers and monomers will be examined in the near future. Critical to process efficiency are the photogenerated TBD strong base and thin film conditions $(\leq 1 \mu \mathrm{m})$, promoting respectively thiolate formation and oxygen permeation.

We think that this novel oxidative photopolymerization might revive interest in this remarkable polymer, with application areas far beyond the normal domains of UV-curing. For example, reductive cleavage of S-S bonds opens the doors to recycling, which is generally unattainable with UV-cured thermoset coatings. Additionally, the interest of UV-patterning extends beyond the fabrication of novel photoresist and may serve for generating robust protein biochips based on a thiol/disulfide exchange protein immobilization strategy.

\section{Supporting Information}

Supporting Information is available from the Wiley Online Library

Received: Month XX, XXXX; Revised: Month XX, XXXX; Published online: 
Keywords: polysulfides, photopolymerization, recycling, photoresists, crosslinking

\section{References}

[1] T. Maeda, H. Otsuka, A. Takahara, Prog. Polym. Sci. 2009, 34, 581.

[2] X. Du, J. Li, A. Welle, L. Li, W. Feng, P. A. Levkin, Adv. Mater. 2015, 27, 4997.

[3] B. D. Fairbanks, S. P. Singh, C. N. Bowman, K. S. Anseth, Macromolecules 2011, 44, 2444.

[4] J. Canadell, H. Goossens, B. Klumperman, Macromolecules 2011, 44, 2536.

[5] Y. Amamoto, H. Otsuka, A. Takahara, K. Matyjaszewski, Adv. Mater. 2012, 24, 3975.

[6] T. F. Scott, A. D. Schneider, W. D. Cook, C. N. Bowman, Science 2005, 308, 1615.

[7] E.-K. Bang, M. Lista, G. Sforazzini, N. Sakai, S. Matile, Chem. Sci. 2012, 3, 1752.

[8] S. Son, E. Shin, B.-S. Kim, Macromolecules 2015, 48, 600.

[9] H. Otsuka, S. Nagano, Y. Kobashi, T. Maeda, A. Takahara, Chem. Commun. 2010, 46, 1150.

[10] P. A. Fernandes, M. J. Ramos, Chem. Eur. J. 2004, 10, 257.

[11] K. Kishore, K. Ganesh, "Polymers containing disulfide, tetrasulfide, diselenide and ditelluride linkages in the main chain", in Polymer Synthesis/Polymer Engineering, Springer Berlin Heidelberg, 1995, p. 81.

[12] G. B. Lowe, Int. J. Adhes. Adhes. 1997, 17, 345.

[13] S. Bauhuber, C. Hozsa, M. Breunig, A. Göpferich, Adv. Mater. 2009, 21, 3286.

[14] D. Vietti, M. Scherrer, "Polymers Containing Sulfur, Polysulfides", in Kirk-Othmer Encyclopedia of Chemical Technology, John Wiley \& Sons, Inc., 2000.

[15] Y. Ding, A. S. Hay, Macromolecules 1996, 29, 4811.

[16] D. J. Phillips, M. I. Gibson, Biomacromolecules 2012, 13, 3200.

[17] E. Q. Rosenthal-Kim, J. E. Puskas, Pure Appl. Chem. 2013, 84, 2121.

[18] Y. Lee, H. Koo, G.-w. Jin, H. Mo, M. Y. Cho, J.-Y. Park, J. S. Choi, J. S. Park, Biomacromolecules 2005, 6, 24.

[19] J. Kamada, K. Koynov, C. Corten, A. Juhari, J. A. Yoon, M. W. Urban, A. C. Balazs, K. Matyjaszewski, Macromolecules 2010, 43, 4133.

[20] W. Choi, F. Sanda, N. Kihara, T. Endo, J. Polym. Sci., Part A: Polym. Chem. 1998, 36, 79. 
[21] E. Q. Rosenthal, J. E. Puskas, C. Wesdemiotis, Biomacromolecules 2011, 13, 154.

[22] K. Arimitsu, R. Endo, Chem. Mater. 2013, 25, 4461.

[23] L. Li, J. Li, X. Du, A. Welle, M. Grunze, O. Trapp, P. A. Levkin, Angew. Chem. Int. Ed. 2014, 53, 3835 .

[24] E. Robert-Banchereau, S. Lacombe, J. Ollivier, Tetrahedron 1997, 53, 2087.

[25] J. Amalric, P. H. Mutin, G. Guerrero, A. Ponche, A. Sotto, J.-P. Lavigne, J. Mater. Chem. 2009, 19, 141.

[26] S. C. Ligon, B. Husár, H. Wutzel, R. Holman, R. Liska, Chem. Rev. 2014, 114, 557.

[27] C. D. Pritchard, T. M. O’Shea, D. J. Siegwart, E. Calo, D. G. Anderson, F. M. Reynolds, J. A. Thomas, J. R. Slotkin, E. J. Woodard, R. Langer, Biomaterials 2011, 32, 587.

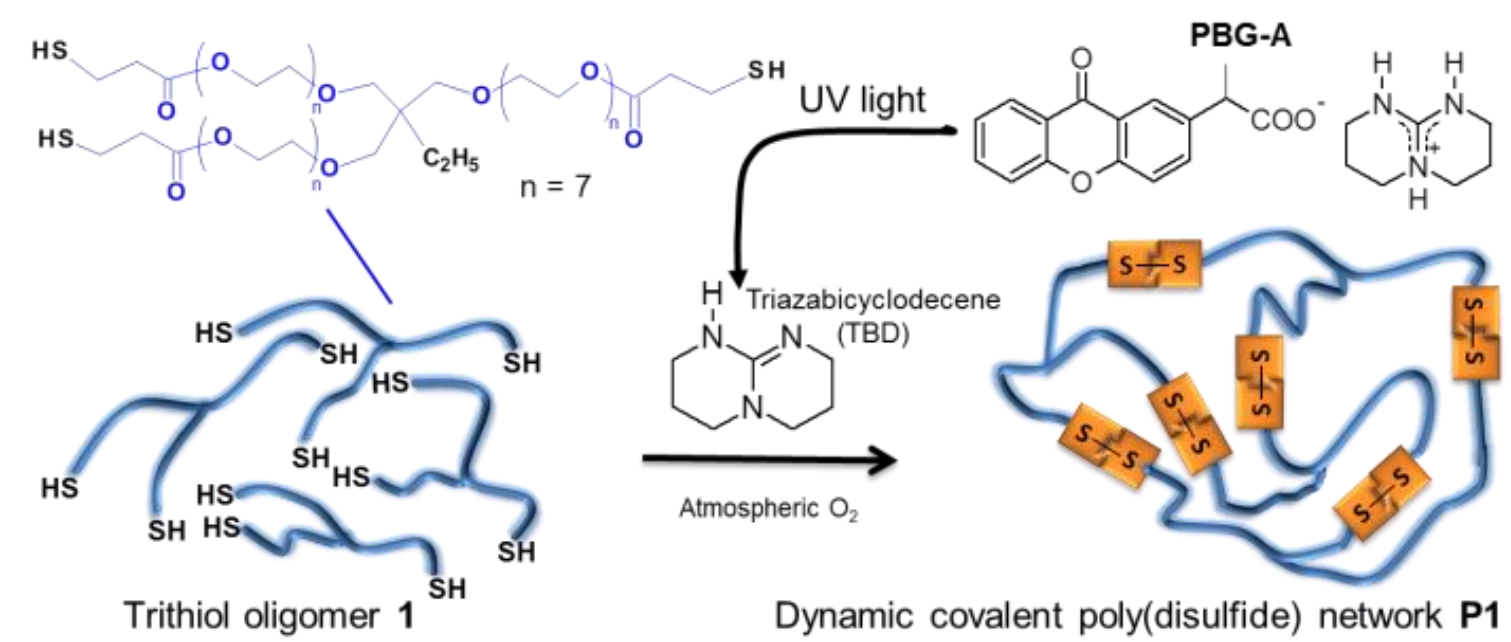

Figure 1. Photobase-catalyzed oxidative polymerization of trithiol oligomer $\mathbf{1 .}$ 

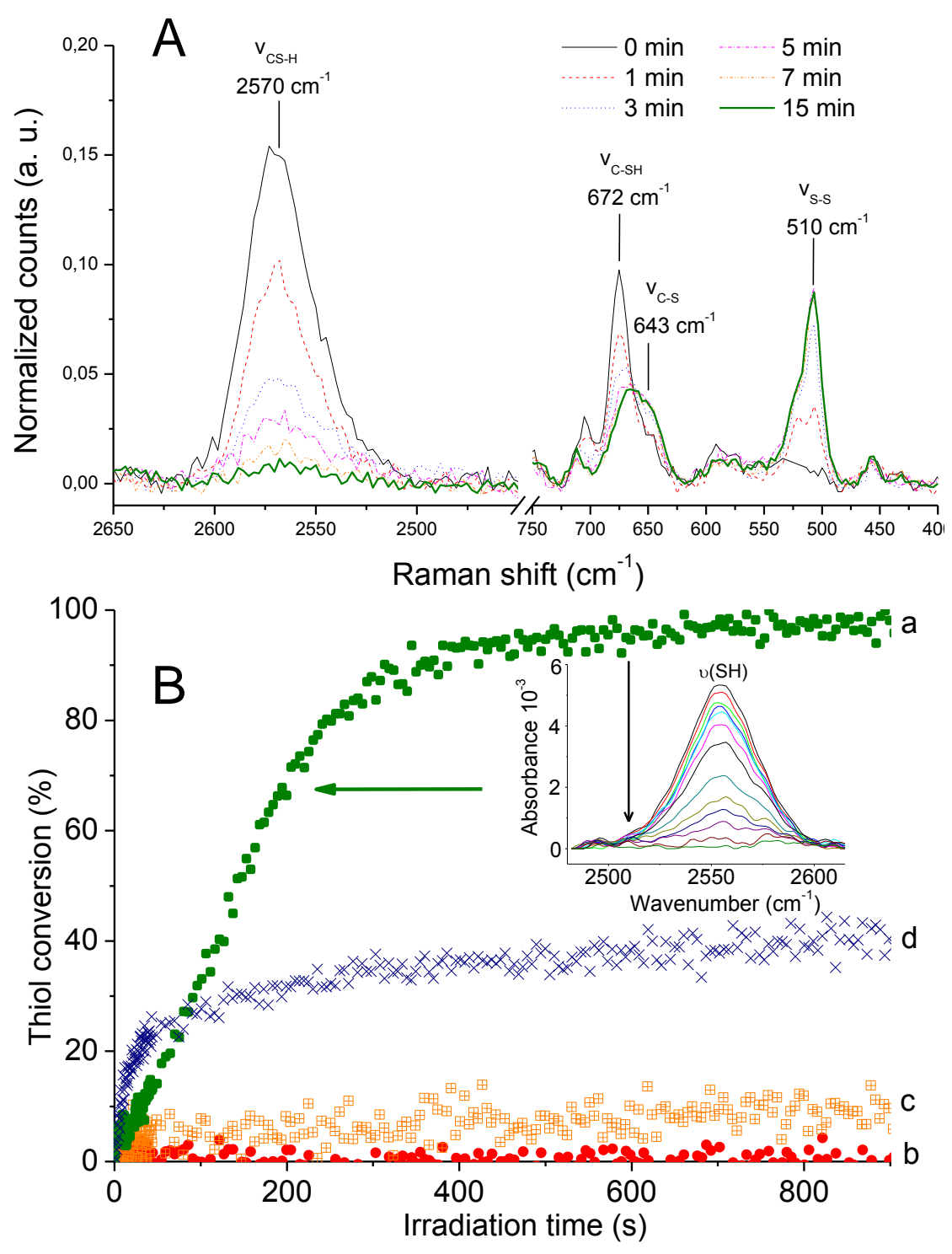

Figure 2. A (top) Raman spectra of 1/PBG-A trithiol film after different UV exposure times: 0, 1, 3, 5, 7 and 15 min. B (bottom) Thiol conversion-time plot obtained from RT-FTIR data during photopolymerization of oligomer 1 under different conditions: (a) with PBG-A in air; (b) without PBG-A in air; (c) with PBG-A under nitrogen atmosphere; and (d) with PBG-B in air. The inset shows the temporal evolution of the IR S-H stretching mode feature at 2555 $\mathrm{cm}^{-1}$ in run a. Irradiation conditions: $\mathrm{Hg}$-Xe lamp $(330-500 \mathrm{~nm})$, irradiance $=290 \mathrm{~mW} / \mathrm{cm}^{2}$. 


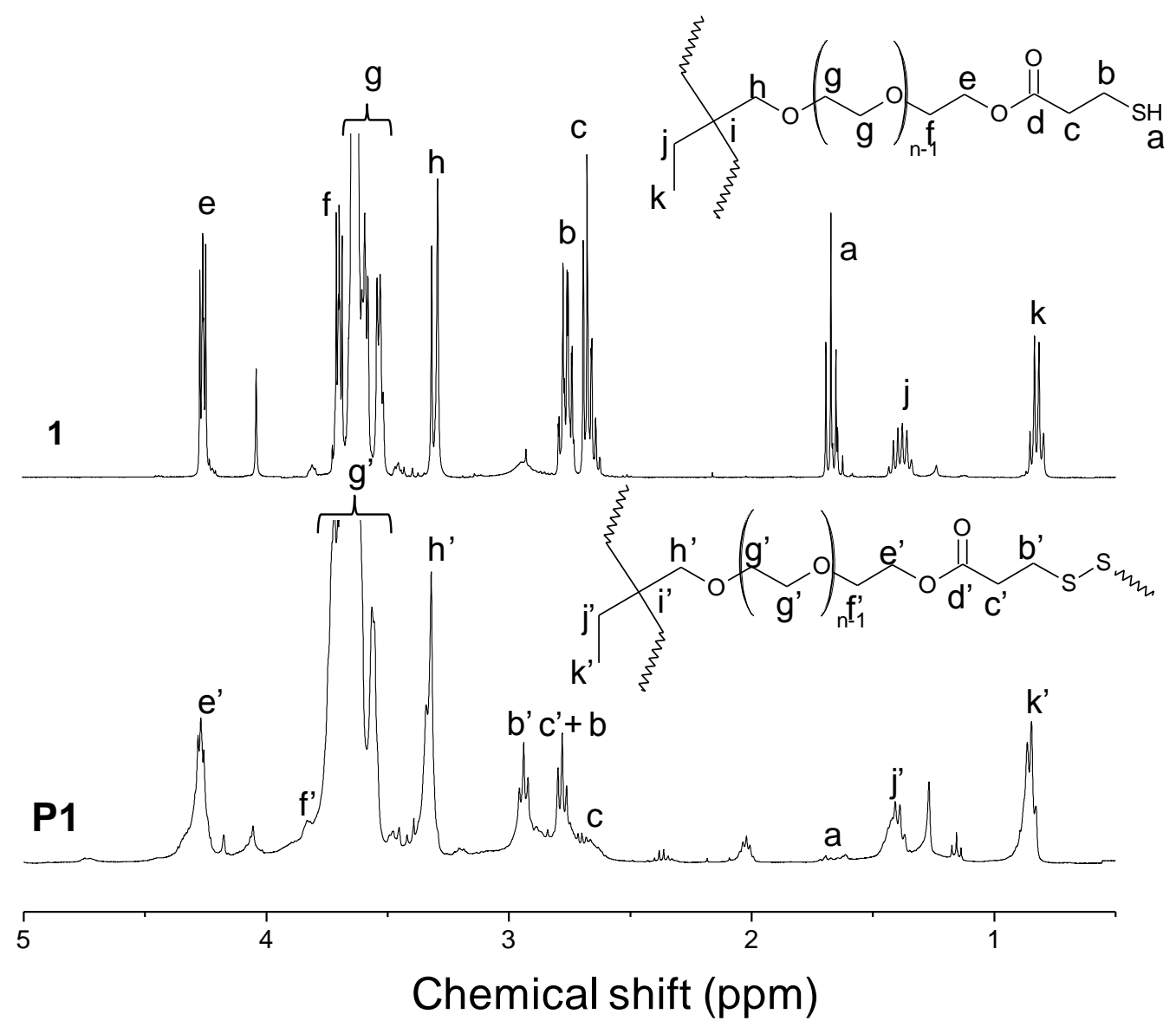

Figure 3. ${ }^{1} \mathrm{H}$ NMR spectrum of the starting trithiol oligomer $\mathbf{1}$ and HR-MAS ${ }^{1} \mathrm{H}$ spectrum of polymer P1. Irradiation conditions: 10 passes under UV conveyor, total light dose $=13.5$ $\mathrm{J} / \mathrm{cm}^{2}, \mathrm{UV}$ exposure time $=2.3 \mathrm{~s}$. 


\section{Photolithography}
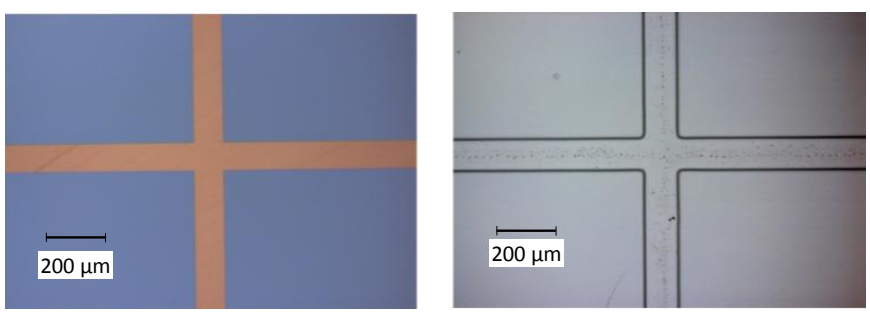

\section{Reductive depolymerization}

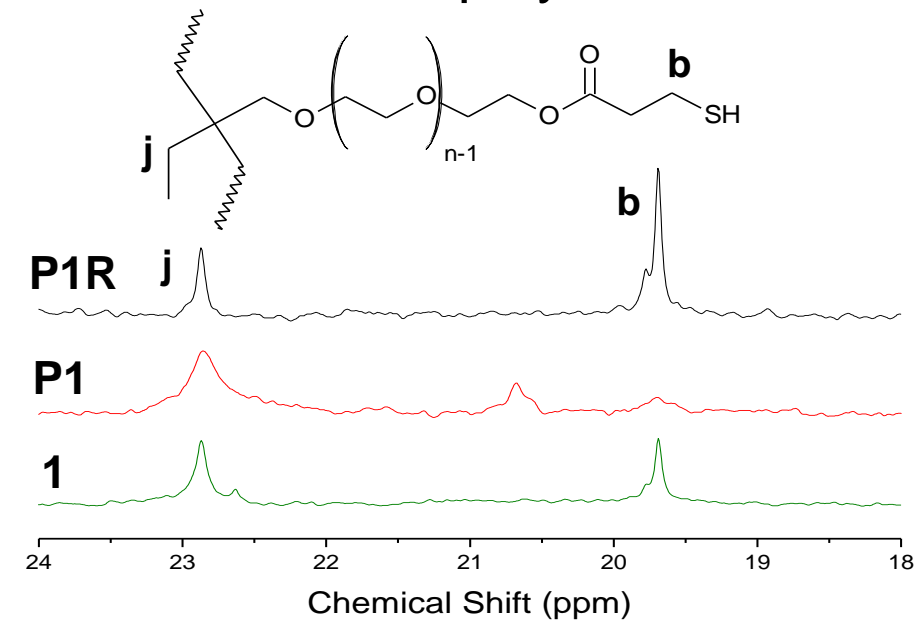

Figure 4. Top. Optical microscopy images of photolithography mask (left) and P1 photopatterned film (right). Bottom. ${ }^{13} \mathrm{C}$ NMR spectra of thiol oligomer 1, poly(disulfide) P1, and the latter polymer after reduction P1R. Irradiation conditions: 10 passes under UV conveyor, total light dose $=13.5 \mathrm{~J} / \mathrm{cm}^{2}, \mathrm{UV}$ exposure time $=2.3 \mathrm{~s}$.

\section{Table of contents entry}

The first oxidative photopolymerization of polythiol film to poly(disulfide) network is described. The process is simple, efficient (100\% conversion in the matter of minutes), highly selective (no over-oxidation), and occurs under ambient conditions. The essential chemistry relies on photogenerated superbases promoting the formation of thiolate anion, which are then subjected to air oxidation.

N. Feillée, A. Chemtob,* C. Ley,* C. Croutxé-Barghorn, X. Allonas, A. Ponche, D. Le Nouen, H. Majjad, L. Jacomine

Photoinduced Cross-linking of Dynamic Poly(disulfide) Films via Thiol Oxidative Coupling 


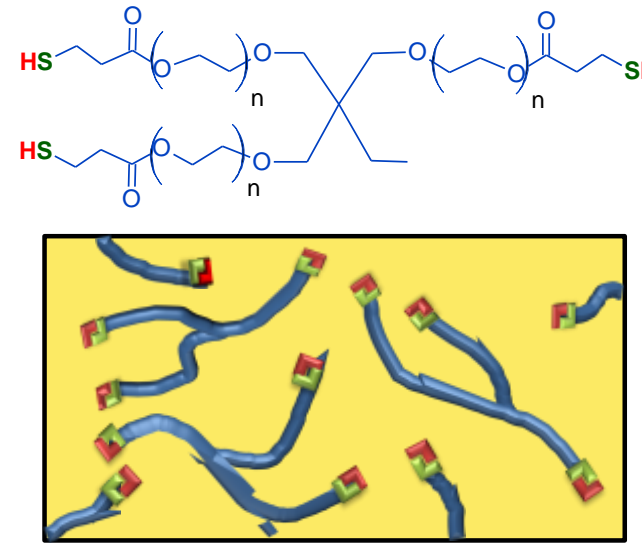

Trithiol oligomer

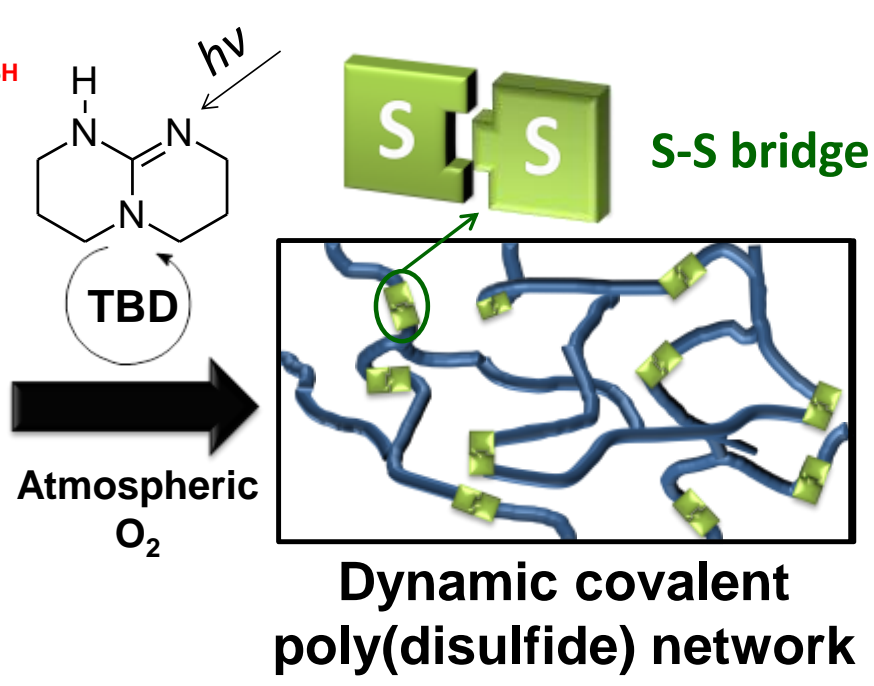




\section{Supporting Information}

for Macromol. Rapid Commun., DOI: 10.1002/marc.2013\#\#\#\#\#

\section{Photoinduced Cross-linking of Dynamic Poly(disulfide) Films via Thiol Oxidative Coupling}

Noémi Feillée, ${ }^{a}$ Abraham Chemtob, ${ }^{a^{*}}$ Christian Ley, ${ }^{a^{*}}$ Céline Croutxé-Barghorn ${ }^{\mathrm{a}}$, Xavier Allonas, ${ }^{a}$ Arnaud Ponche, ${ }^{b}$ Didier Le Nouen, ${ }^{c}$ Hicham Majjad, ${ }^{d}$ Léandro Jacomine ${ }^{e}$

\section{General methods and materials}

\section{Materials}

Ethoxylated trimethylolpropane tri(3-mercaptopropionate) $(\mathbf{1}, 1300 \mathrm{~g} / \mathrm{mol})$ was provided by Bruno Bock. 2-(9-Oxoxanthen-2-yl)propionic acid 1,5,7-triazabicyclo[4.4.0]dec-5-ene salt (PBG-A) and DL-dithiothreitol were purchased from TCI. Irgacure 907 (PBG-B) is a gift from BASF Specialty Chemicals. Triethylamine (> $99 \%)$ and chloroform $(>99.5 \%)$ were purchased from Sigma-Aldrich. All reagents were used as received without further purification.

\section{Poly(disulfide) films via photobase-catalyzed air oxidation of thiol}

The formulation was prepared by adding $20 \mathrm{mg}$ of PBG-A to a chloroform solution $(\mathrm{V}=4 \mathrm{~mL})$ containing $0.48 \mathrm{~g}$ of oligomer $\mathbf{1}$. The homogeneous and photolatent mixture was then deposited on a $\mathrm{KBr}$ or glass substrate using a spin-coater to achieve a $1 \mu \mathrm{m}$ thick film assessed by profilometry measurements (3D surface profiler Bruker). Two UV irradiation devices were implemented for oxidation photopolymerization yielding poly(disulfide) P1. First, UV irradiation in air was performed at ambient temperature during $900 \mathrm{~s}$ using a medium-pressure Hg-Xe arc lamp (Hamamatsu L8251, $200 \mathrm{~W}$ ) coupled with a flexible light-guide. The emitted light was filtered $(\lambda>330 \mathrm{~nm})$ to prevent self-dissociation of thiol functions, and directed perpendicular to the specimen film placed $3 \mathrm{~cm}$ away. A total irradiance of $290 \mathrm{~mW} / \mathrm{cm}^{2}$ was 
measured at the surface of the film sample by conventional radiometric techniques. The irradiation device was also equipped with an elliptical reflector $(365 \mathrm{~nm})$ that efficiently reflects the UV light, and lets heat rays pass through, preventing any significant increase of temperature. Using this cold reflector cutting off heat, the local temperature during the process may be increased of ca. $3{ }^{\circ} \mathrm{C}$. For experiments performed under nitrogen, the sample was performed in a controlled-environment chamber where temperature and atmosphere were finely adjusted. Light entry into the chamber was enabled by a $\mathrm{KBr}$ window transparent to UV light. This focalized UV lamp was used to conduct in situ RT-FTIR experiments. Alternatively, UV exposure was carried out at by ten successive passes under a UV conveyor (Qurtech) equipped with an H-bulb lamp (Fusion). The belt speed of the conveyor was set to $10 \mathrm{~m} / \mathrm{min}$. Under these conditions, the emitted light dose for each pass is $1.35 \mathrm{~J} / \mathrm{cm}^{2}$ (UVA [320-390 nm]: $0.46 \mathrm{~J} / \mathrm{cm}^{2}$, UVB [280-320 $\mathrm{nm}]: 0.31 \mathrm{~J} / \mathrm{cm}^{2}$, UVC [250-260 nm]: $0.08 \mathrm{~J} / \mathrm{cm}^{2}$ and UVV [395-445 $\left.\mathrm{nm}\right]: 0.50 \mathrm{~J} / \mathrm{cm}^{2}$ ) and corresponds to an exposure time of $0.23 \mathrm{~s}$.

\section{Photopatterning of poly(disulfide) film}

A similar 1/PBG-A/ $\mathrm{CHCl}_{3}$ formulation was deposited on glass substrate with a spin-coater to achieve an effective thickness of $1 \mu \mathrm{m}$. The substrate was then placed at $40 \mu \mathrm{m}$ of a crosspatterned mask in a SUSS MicroTech mask aligner and irradiated for 15 min under a HBO Osram UV lamp (14 $\left.\mathrm{mW} / \mathrm{cm}^{2}\right)$. After irradiation, the substrate was dipped into an acetone bath for $5 \mathrm{~s}$ to remove the unpolymerized parts.

\section{Reduction of poly(disulfide) P1 in presence of DTT}

$0.1 \mathrm{~g}$ of polymer P1 (0.12 mmol of disulfide bonds) was added as powder to $50 \mathrm{~mL}$ of chloroform under vigorous stirring. Subsequently, $0.15 \mathrm{~g}$ of dithiothreitol $(0.96 \mathrm{mmol})$ and $9 \mathrm{mg}$ of $\mathrm{Et}_{3} \mathrm{~N}(0.09 \mathrm{mmol})$ were added to the latter insoluble mixture. After 12 days of reaction, the 
solid aggregates disappeared, and a turbid solution was formed. The resultant organic solution was washed with $50 \mathrm{~mL}$ of saturated $\mathrm{NaCl}$ aqueous solution to extract the water-soluble oxidized and reduced DTT species. The organic phase was evaporated and the sticky resin was analyzed by NMR.

\section{Characterization}

Raman spectra were collected using an In via Raman reflex microscope from Renishaw. The excitation wavelength was provided by a He-Ne laser from Renishaw emitting $17 \mathrm{~mW} / \mathrm{cm}^{2}$ at $633 \mathrm{~nm}$. The objective used was N PLAN 50x Leica with a numerical aperture of 0.75. A 600 1/mm grating optimized for visible light was used to disperse the light on a CCD NIR deep depletion Peltier cooled detector camera. A 30 s exposure and 10 spectra accumulation were needed to obtain a reasonable signal-to-noise ratio. The conversion rate of thiol functions was determined by integration of the Raman SH stretching band at $2570 \mathrm{~cm}^{-1}$ before and after irradiation. X-ray photoelectron spectrometry (XPS) analysis was carried out using a Gammadata Scienta SES 2002 X-ray photoelectron spectrometer under ultra-high vacuum (P < $10^{-9}$ mbar). The monochromated $\mathrm{Al} \mathrm{K} \alpha$ source was operated at a current of $30 \mathrm{~mA}$ and $14 \mathrm{kV}$, with a $90^{\circ}$ nominal take-off angle (angle between the sample surface and photoemission direction). During acquisition, the pass energy was set to $200 \mathrm{eV}$ for high-resolution spectra. Classical Scofield sensitivity factors were used for peak fitting procedures with CASAXPS software: S2p 1.68. All line shapes used in peak fitting procedures were a mix of $30 \%$ Gaussian and $70 \%$ Lorentzian shapes. Real-time Fourier transform infrared (RT-FTIR) spectra were obtained with a Bruker Vertex 70 spectrophotometer equipped with a liquid nitrogen cooled mercury-cadmium-telluride (MCT) detector working in the rapid scan mode. The resolution of the spectra was $4 \mathrm{~cm}^{-1}$ with an average of 4 scans/s. The conversion rate of thiol functions over time was determined by integration of the $\mathrm{SH}$ stretching band at $2555 \mathrm{~cm}^{-1}$. Thermal 
gravimetric analysis (TGA) was carried out with a TGA Q500 (TA Instruments) under nitrogen atmosphere (20 mL/min). $9 \mathrm{mg}$ of poly(disulfide) film was placed in an open aluminum pan and heated from ambient conditions to $900{ }^{\circ} \mathrm{C}$ at $10{ }^{\circ} \mathrm{C} / \mathrm{min}^{-1}$. Differential scanning calorimetry (DSC) was carried out on a TA Q2000 DSC using a heat-cool-heat thermal cycle. $5 \mathrm{mg}$ of poly(disulfide) film was placed in an hermetic aluminum pan. The first cycle started by heating the sample from -90 to $100{ }^{\circ} \mathrm{C}$ at $10{ }^{\circ} \mathrm{C} / \mathrm{min}$. The second cycle cooled the sample back to -90 ${ }^{\circ} \mathrm{C}$. The third step heated the sample again from -90 to $100{ }^{\circ} \mathrm{C}$ at $10{ }^{\circ} \mathrm{C} / \mathrm{min} .{ }^{1} \mathbf{H}$ NMR (400 MHz) and ${ }^{13} \mathbf{C}$ NMR (100 MHz) spectra were recorded at room temperature on a Bruker Advance 400 spectrometer equipped with $5 \mathrm{~mm}$ Z-gradient QNP $\left({ }^{1} \mathrm{H},{ }^{13} \mathrm{C}\right)$ probe for routine spectroscopy or $4 \mathrm{~mm}\left({ }^{1} \mathrm{H},{ }^{13} \mathrm{C}\right)$ Z-gradient HR-MAS probe for supramolecular gel. The chemical shifts were referenced to the residual proton signal of the solvents $\mathrm{CHCl}_{3}$ at $7.26 \mathrm{ppm}$ for ${ }^{1} \mathrm{H}$ and $77.03 \mathrm{ppm}$ for ${ }^{13} \mathrm{C}$.

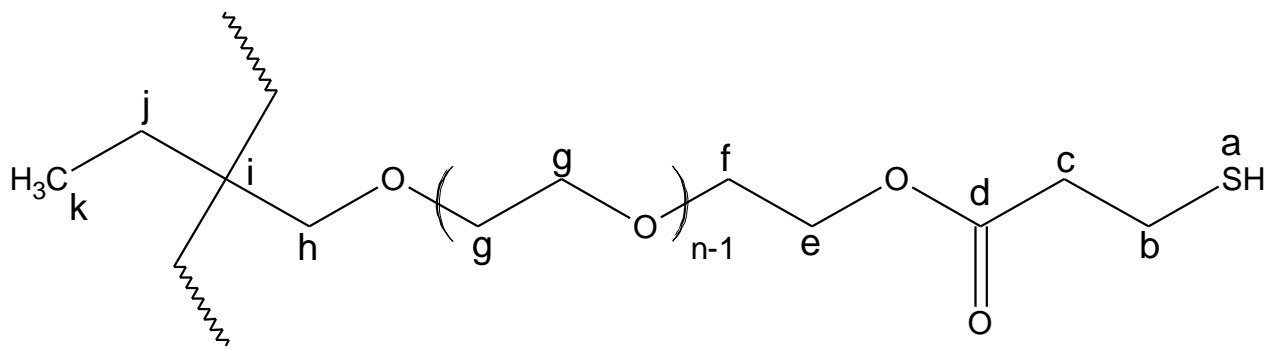

Oligomer 1. ${ }^{1} \mathrm{H}$ NMR (400 MHz, $\left.\mathrm{CDCl}_{3}\right), \delta 4.25 \mathrm{ppm}\left(\mathrm{m}, 2 \mathrm{H}, \mathrm{H}_{\mathrm{e}}\right), 3.69 \mathrm{ppm}\left(\mathrm{m}, 2 \mathrm{H}, \mathrm{H}_{\mathrm{f}}\right)$, 3.66-3.5ppm (m, $\left.(\mathrm{n}-1) \times 2 \mathrm{H}, \mathrm{H}_{\mathrm{g}}\right), 3.32$ and $3.29 \mathrm{ppm}\left(\mathrm{s}, 2 \mathrm{H}, \mathrm{H}_{\mathrm{h}}\right), 2.75 \mathrm{ppm}\left(\mathrm{m}, 2 \mathrm{H}, \mathrm{H}_{\mathrm{b}}\right)$, 2.67ppm (m, 2H, $\left.\mathrm{H}_{\mathrm{c}}\right), 1.67 \mathrm{ppm}\left(\mathrm{t}, \mathrm{J}=8.3 \mathrm{~Hz}, 1 \mathrm{H}, \mathrm{H}_{\mathrm{a}}\right), 1.38 \mathrm{ppm}\left(\mathrm{m}, 2 \mathrm{H}, \mathrm{H}_{\mathrm{j}}\right), 0.82 \mathrm{ppm}(\mathrm{m}, 3 \mathrm{H}$, $\left.\mathrm{H}_{\mathrm{k}}\right) .{ }^{13} \mathrm{C}$ NMR $\left(100 \mathrm{MHz}, \mathrm{CDCl}_{3}\right), \delta 171.5 \mathrm{ppm}\left(\mathrm{C}_{\mathrm{d}}\right)$, 71.5ppm $\left(\mathrm{C}_{\mathrm{h}}\right), 70.6 \mathrm{ppm}\left(\mathrm{C}_{\mathrm{g}}\right), 69.0 \mathrm{ppm}$ $\left(\mathrm{C}_{\mathrm{f}}\right)$, 63.7ppm $\left(\mathrm{C}_{\mathrm{e}}\right)$, 43.2ppm $\left(\mathrm{C}_{\mathrm{i}}\right)$, 38.4ppm $\left(\mathrm{C}_{\mathrm{c}}\right)$, 22.9ppm $\left(\mathrm{C}_{\mathrm{j}}\right)$, 19.7ppm $\left(\mathrm{C}_{\mathrm{b}}\right)$, 7.6ppm $\left(\mathrm{C}_{\mathrm{k}}\right)$.

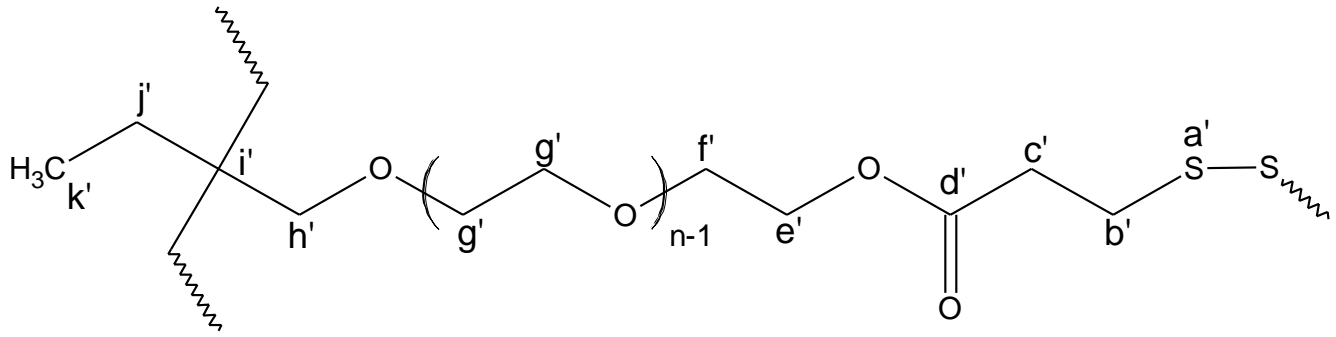

Poly(disulfide) P1. ${ }^{1} \mathrm{H}$ NMR (400 MHz, $\left.\mathrm{CDCl}_{3}\right), \delta 4.25 \mathrm{ppm}\left(\mathrm{m}, 2 \mathrm{H}, \mathrm{H}_{\mathrm{e}}\right), 3.7 \mathrm{ppm}(\mathrm{m}, 2 \mathrm{H}$, $\left.\mathrm{H}_{\mathrm{f}^{\prime}}\right)$, 3.66-3.5ppm (m, (n-1) $\left.\times 2 \mathrm{H}, \mathrm{H}_{\mathrm{g}}{ }^{\prime}\right), 3.33-3.22 \mathrm{ppm}\left(\mathrm{m}, 2 \mathrm{H}, \mathrm{H}_{\mathrm{h}^{\prime}}\right), 2.92 \mathrm{ppm}\left(\mathrm{m}, 2 \mathrm{H}, \mathrm{H}_{\mathrm{b}^{\prime}}\right)$, 2.76ppm $\left(\mathrm{m}, 2 \mathrm{H}, \mathrm{H}_{\mathrm{c}^{\prime}}\right), 1.39 \mathrm{ppm}\left(\mathrm{m}, 2 \mathrm{H}, \mathrm{H}_{\mathrm{j}}\right), 0.83 \mathrm{ppm}\left(\mathrm{m}, 3 \mathrm{H}, \mathrm{H}_{\mathrm{k}^{\prime}}\right) .{ }^{13} \mathrm{C} \mathrm{NMR}(100 \mathrm{MHz}$, 
$\left.\mathrm{CDCl}_{3}\right), \delta$ 171.6ppm $\left(\mathrm{C}_{\mathrm{d}^{\prime}}\right), 71.5 \mathrm{ppm}\left(\mathrm{C}_{\mathrm{h}^{\prime}}\right), 70.6 \mathrm{ppm}\left(\mathrm{C}_{\mathrm{g}}\right)$, 69.1ppm $\left(\mathrm{C}_{\mathrm{f}^{\prime}}\right), 63.9 \mathrm{ppm}\left(\mathrm{C}_{\mathrm{e}^{\prime}}\right)$, 43.3ppm $\left(\mathrm{C}_{\mathrm{i}^{\prime}}\right)$, 34.0ppm $\left(\mathrm{C}_{\mathrm{b}^{\prime}}\right)$, 33.0ppm $\left(\mathrm{C}_{\mathrm{c}^{\prime}}\right)$, 22.9ppm $\left(\mathrm{C}_{\mathrm{j}^{\prime}}\right)$, 7.7ppm $\left(\mathrm{C}_{\mathrm{k}^{\prime}}\right)$.

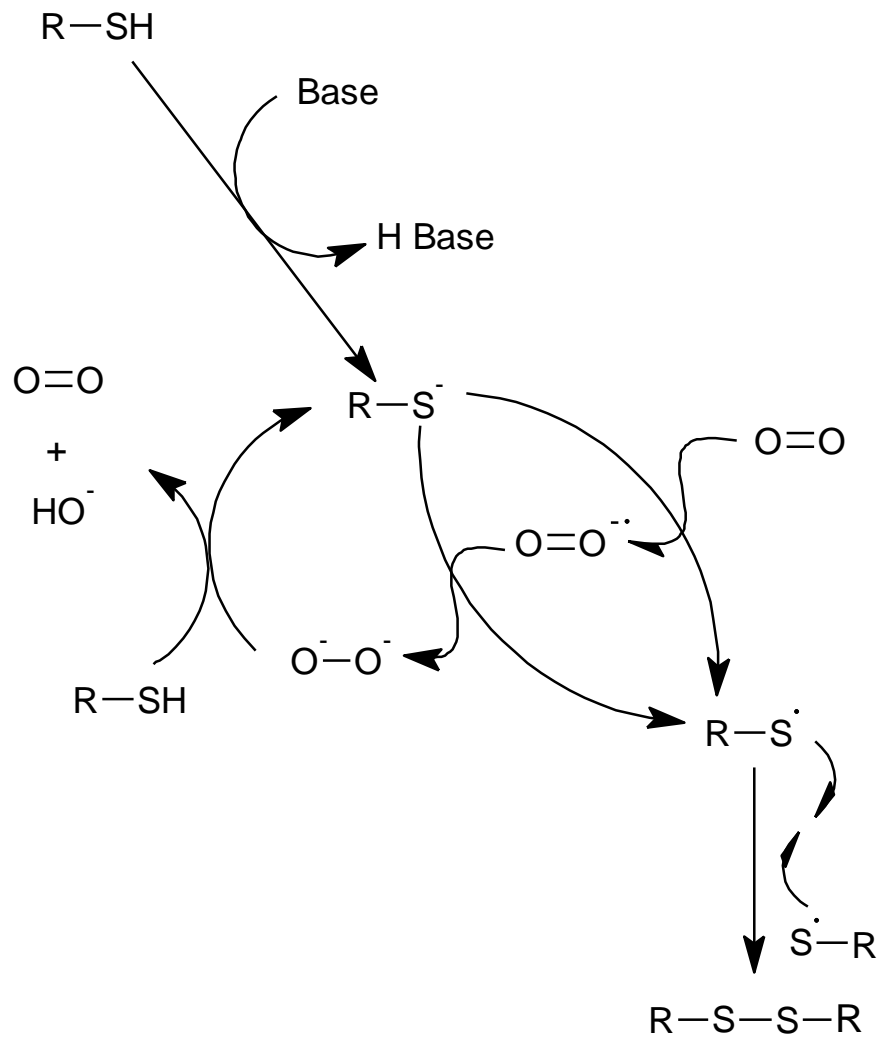

Scheme S1. Mechanism of base-catalyzed thiol oxidation with oxygen as an oxidative reactant
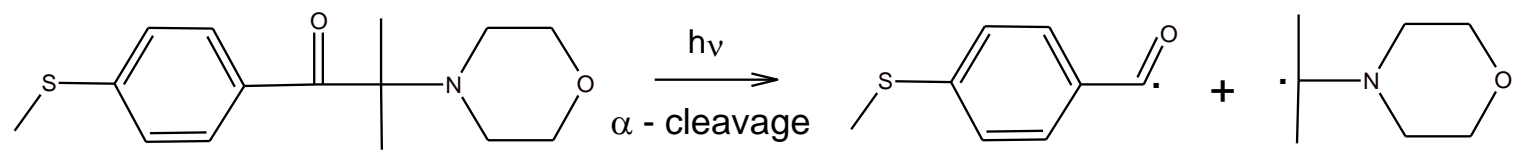

PBG B

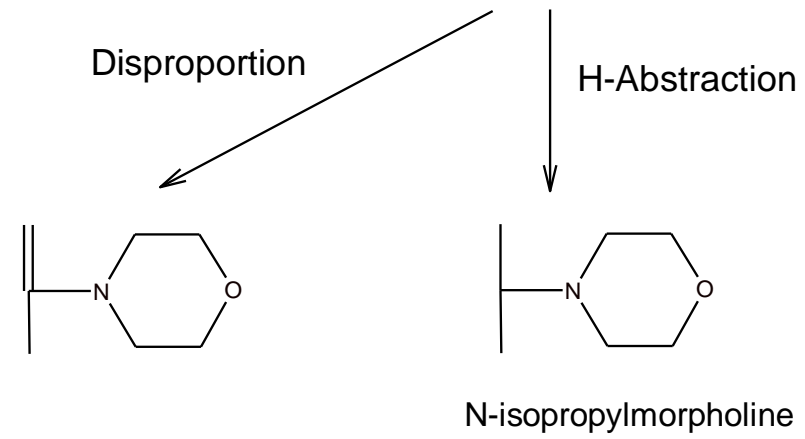

Scheme S2. Mechanism of photoinduced generation of N-isopropylmorpholine photobase from PBG-B 
S2p

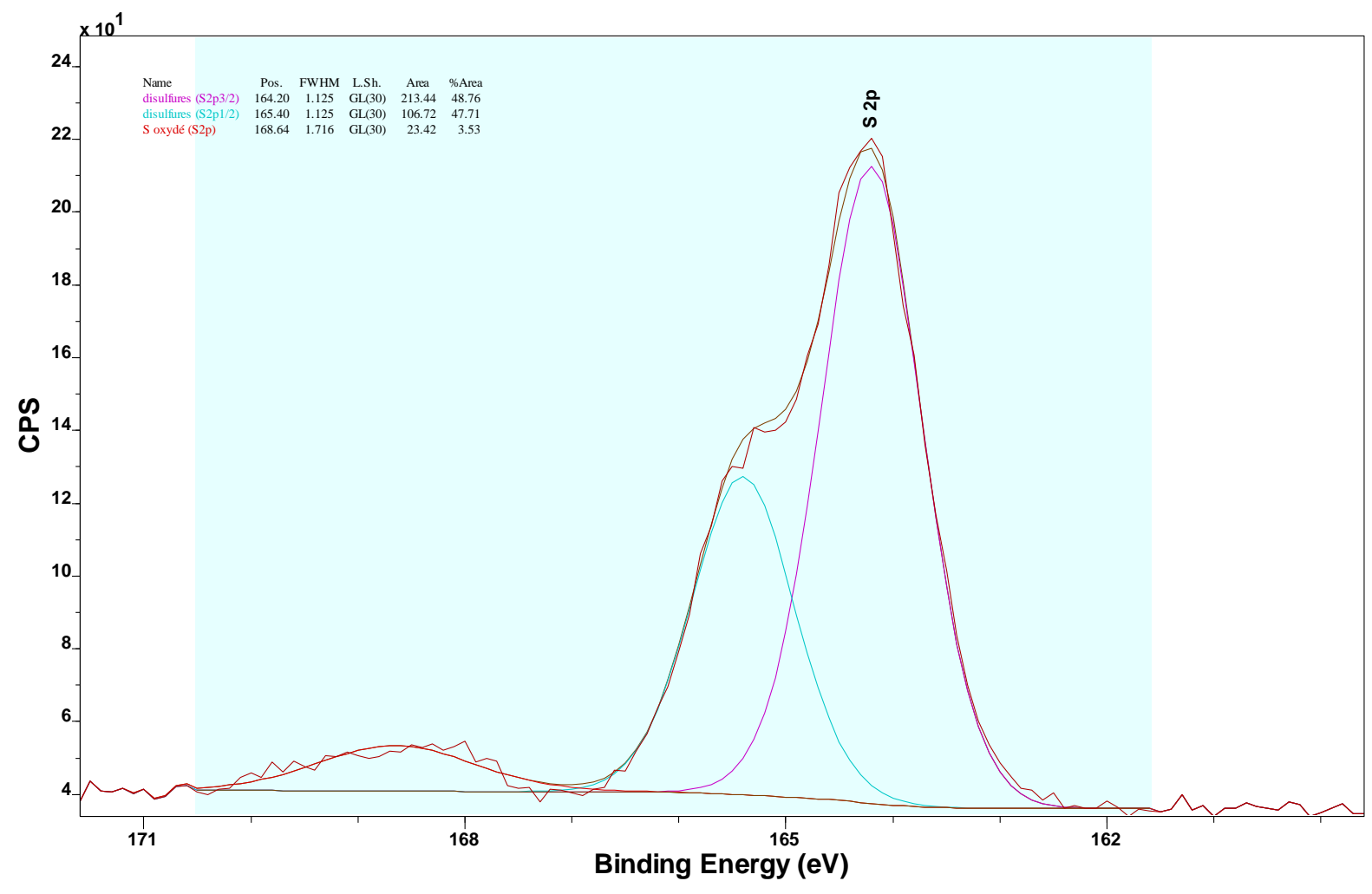

Figure S1. $S_{2 p}$ spectra of polymer P1. Irradiation conditions: 10 passes under UV conveyor, total light dose $=13.5 \mathrm{~J} / \mathrm{cm}^{2}$, UV exposure time $=2.3 \mathrm{~s}$. 
(a)

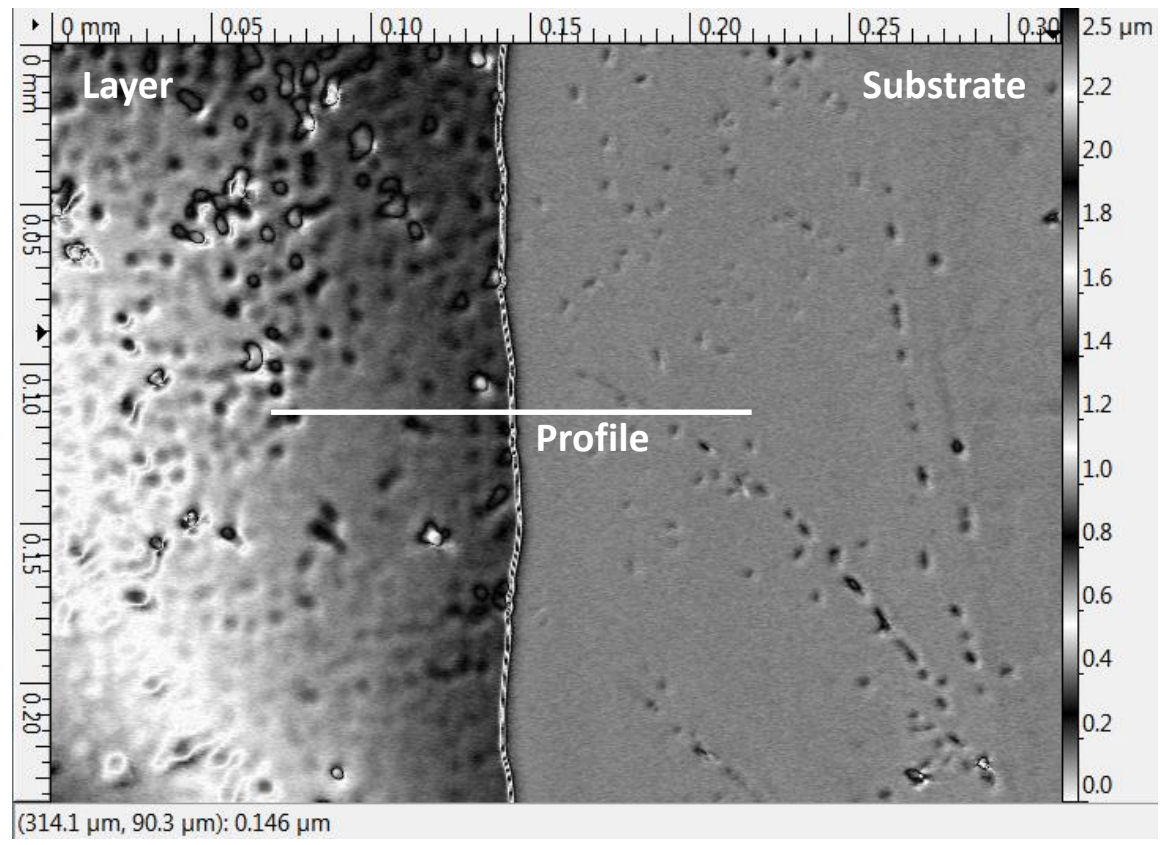

(b)

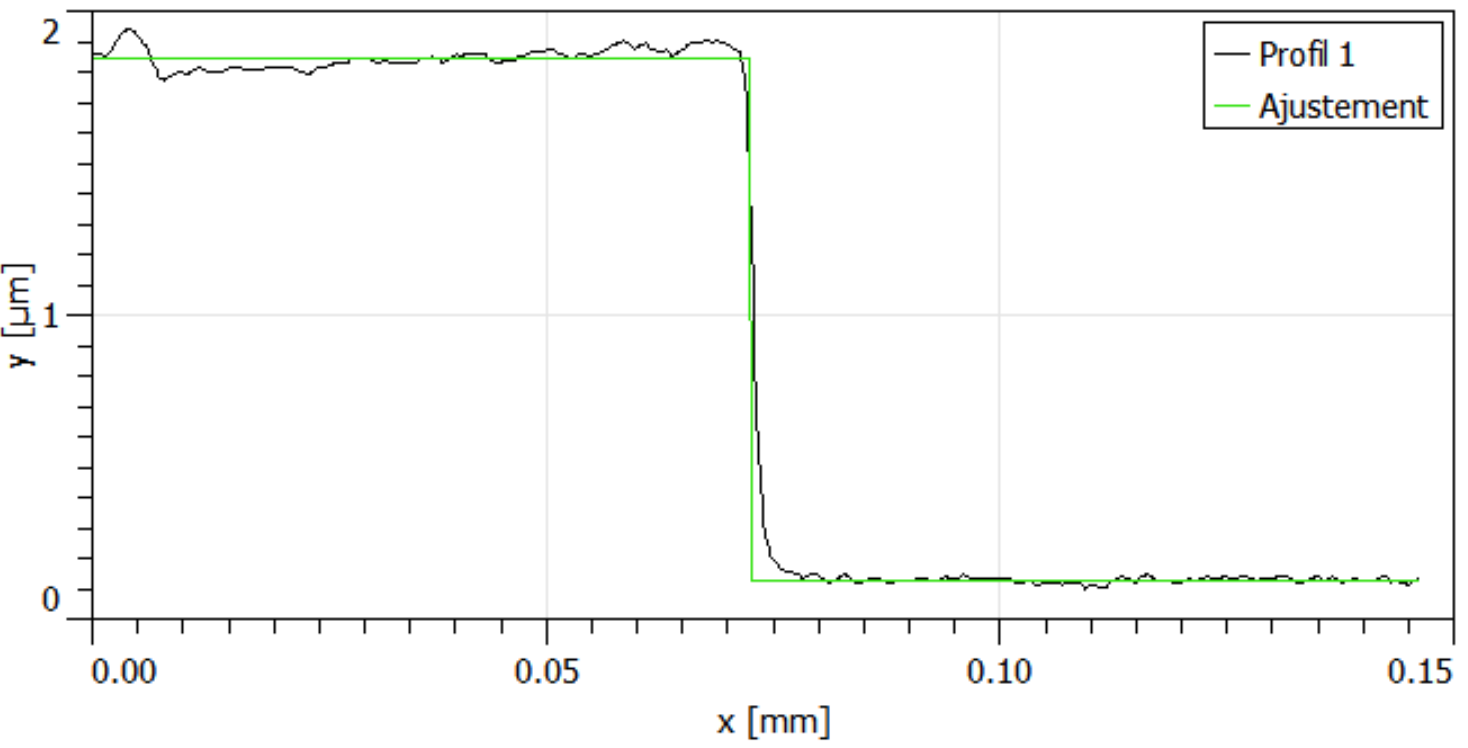

Figure S2. Thickness measurement of the trithiol film 1 before UV exposure using 3D optical profilometry. (a) Initial scanned surface; (b) fit to access the thickness value. 


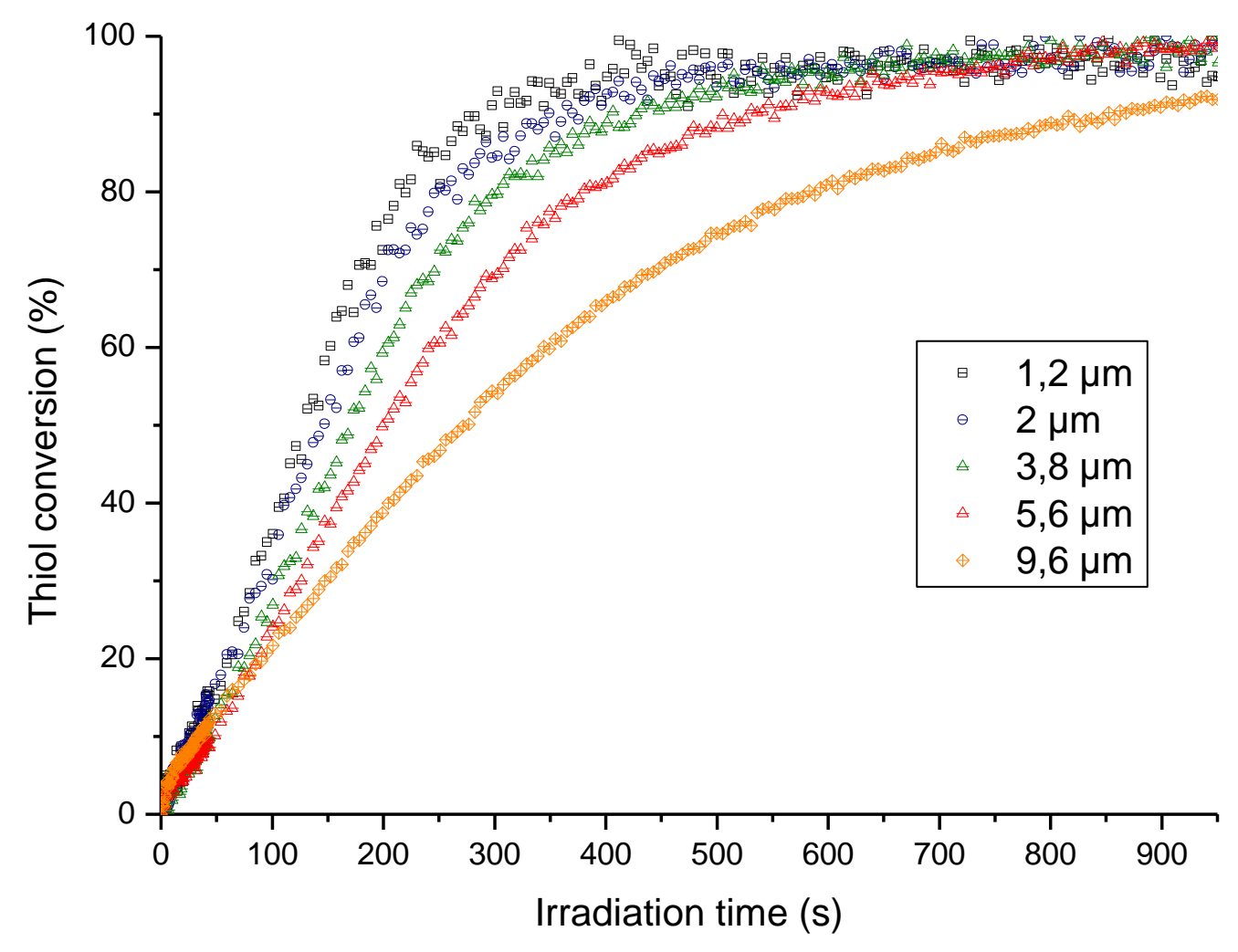

Figure S3. Effect of 1/PBG-A film thickness on thiol oxidation kinetics (RT-FTIR data). Irradiation conditions: Hg-Xe lamp (330-500 nm), irradiance $=290 \mathrm{~mW} / \mathrm{cm}^{2}$.

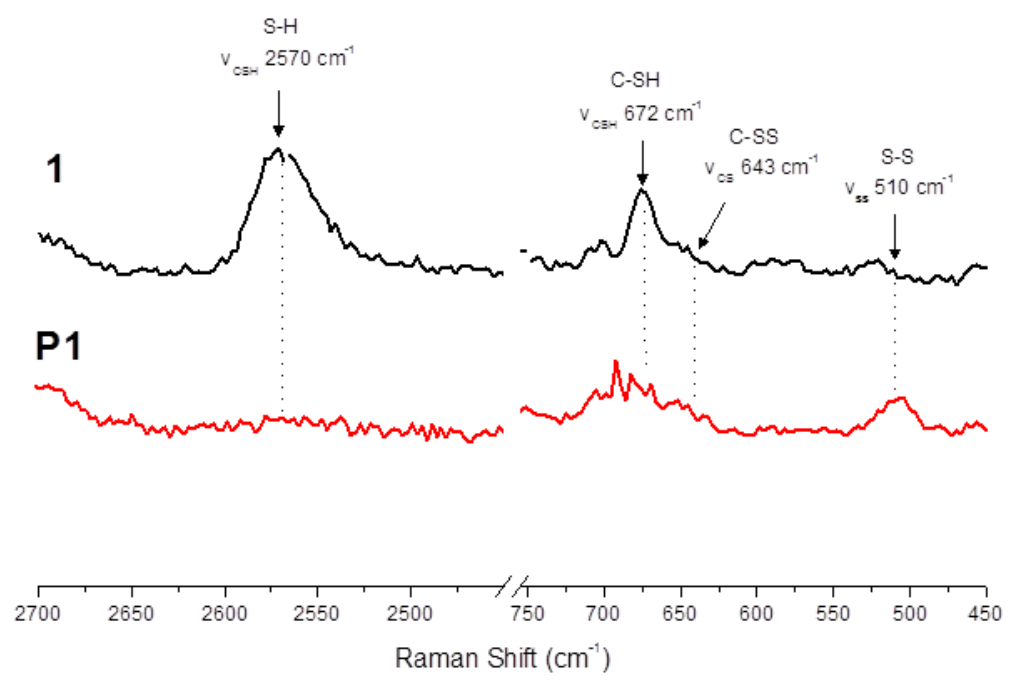

Figure S4. Raman spectra of thiol oligomer 1 and disulfide polymer P1. Irradiation conditions: 10 passes under UV conveyor, total light dose $=13.5 \mathrm{~J} / \mathrm{cm}^{2}$, UV exposure time $=2.3 \mathrm{~s}$ 

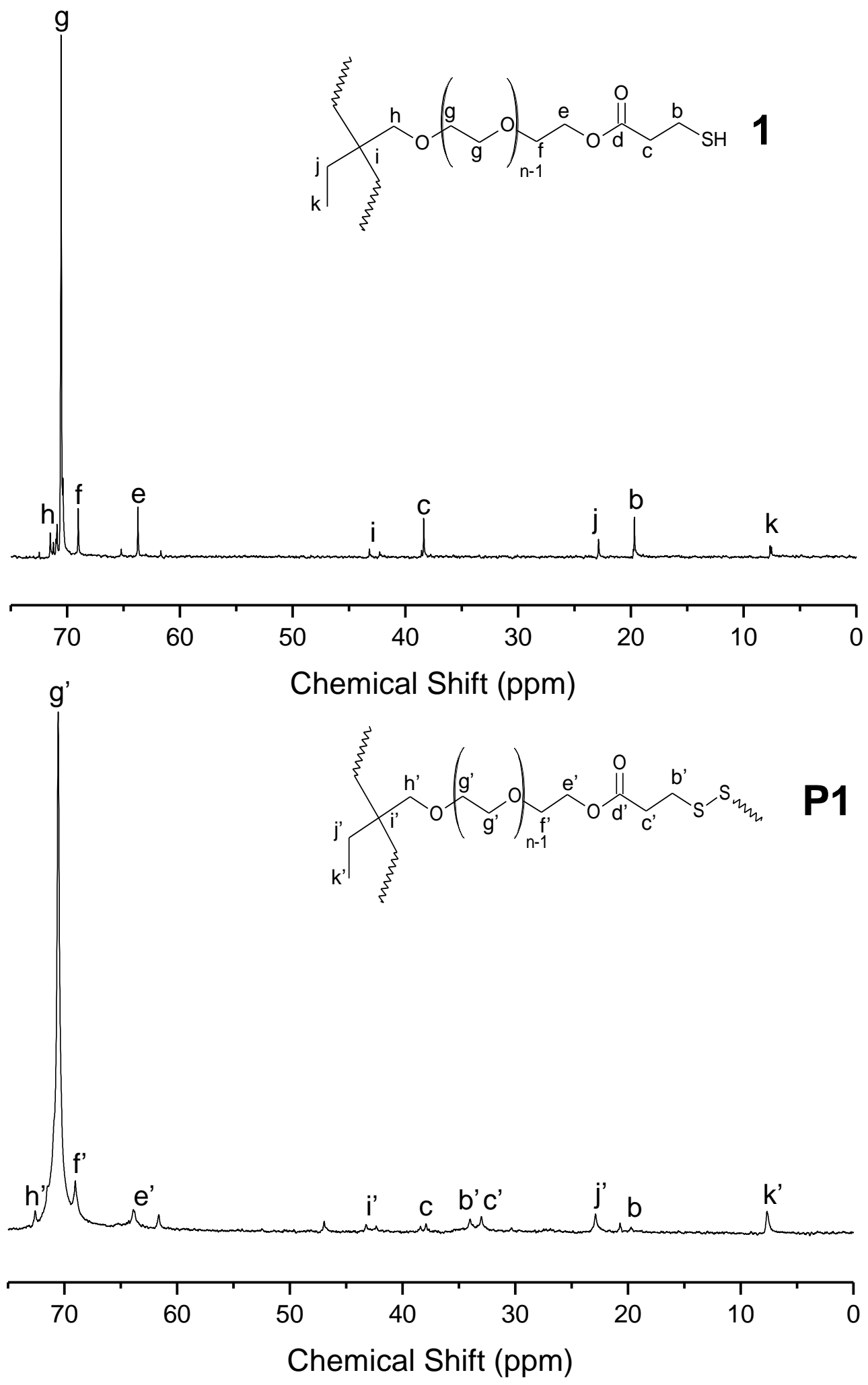

Figure S5. ${ }^{13} \mathrm{C}$ NMR spectra of oligomer 1 and polymer P1. Irradiation conditions: 10 passes under UV conveyor, total light dose $=13.5 \mathrm{~J} / \mathrm{cm}^{2}$, UV exposure time $=2.3 \mathrm{~s}$ 


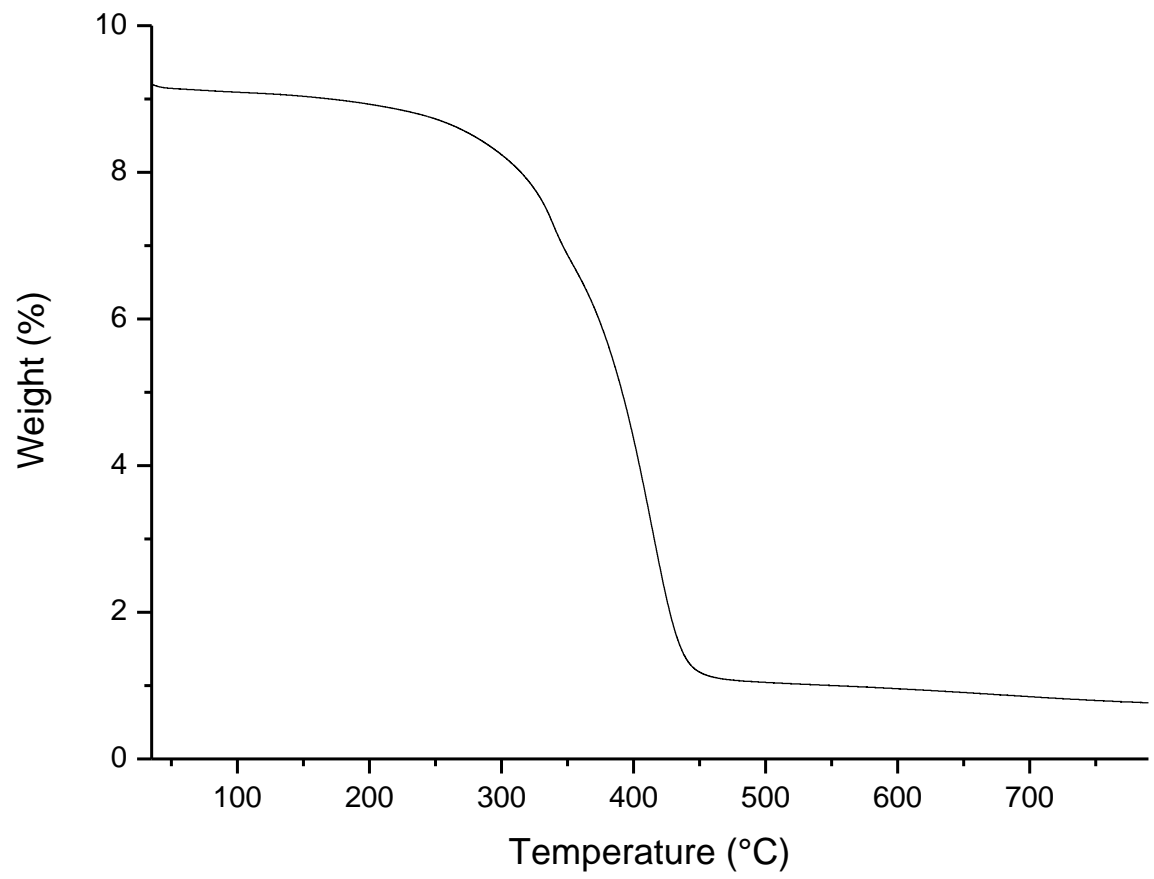

Figure S6. TGA thermogram of P1. Irradiation conditions: 10 passes under UV conveyor, total light dose $=13.5 \mathrm{~J} / \mathrm{cm}^{2}, \mathrm{UV}$ exposure time $=2.3 \mathrm{~s}$

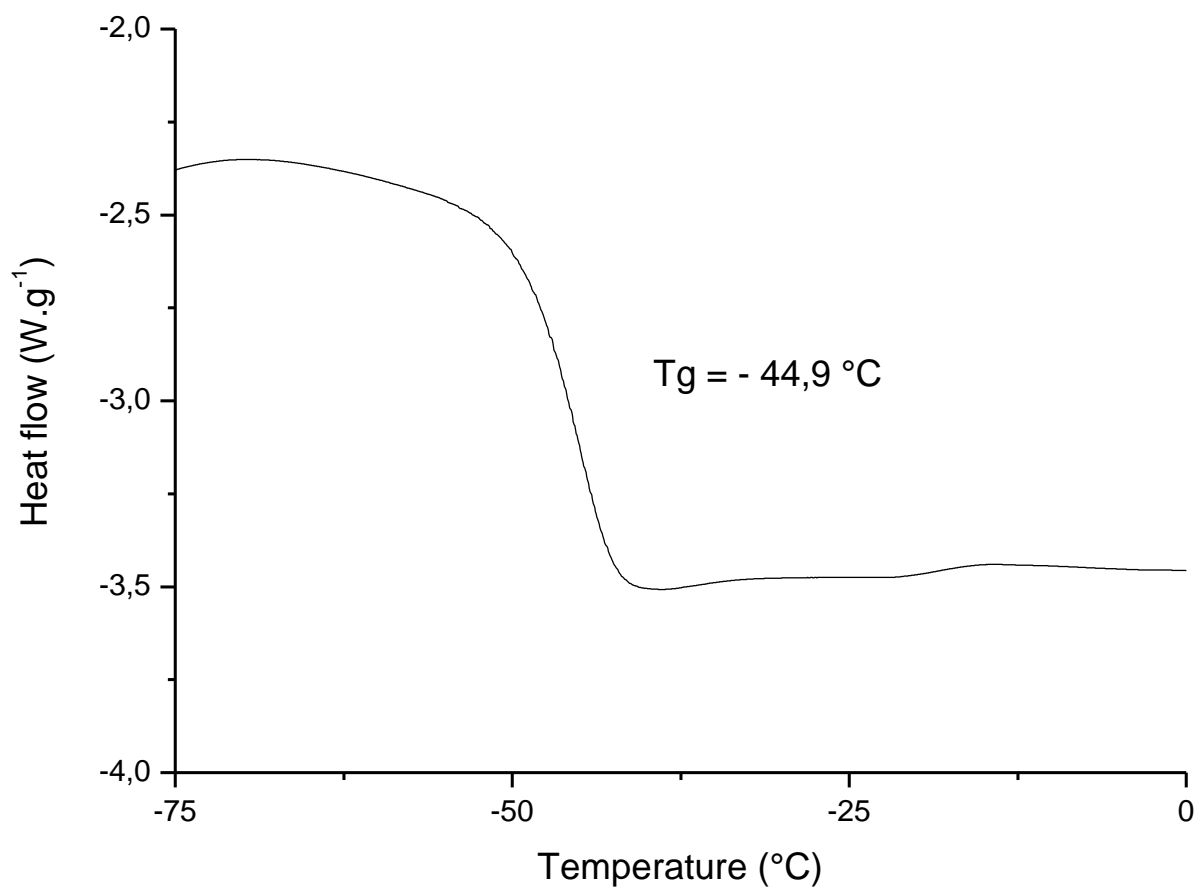

Figure S7. DSC thermogram of $\mathbf{P 1}$ (Heating ramp of $10{ }^{\circ} \mathrm{C} / \mathrm{min}$ ). Irradiation conditions: 10 passes under UV conveyor, total light dose $=13.5 \mathrm{~J} / \mathrm{cm}^{2}, \mathrm{UV}$ exposure time $=2.3 \mathrm{~s}$. 


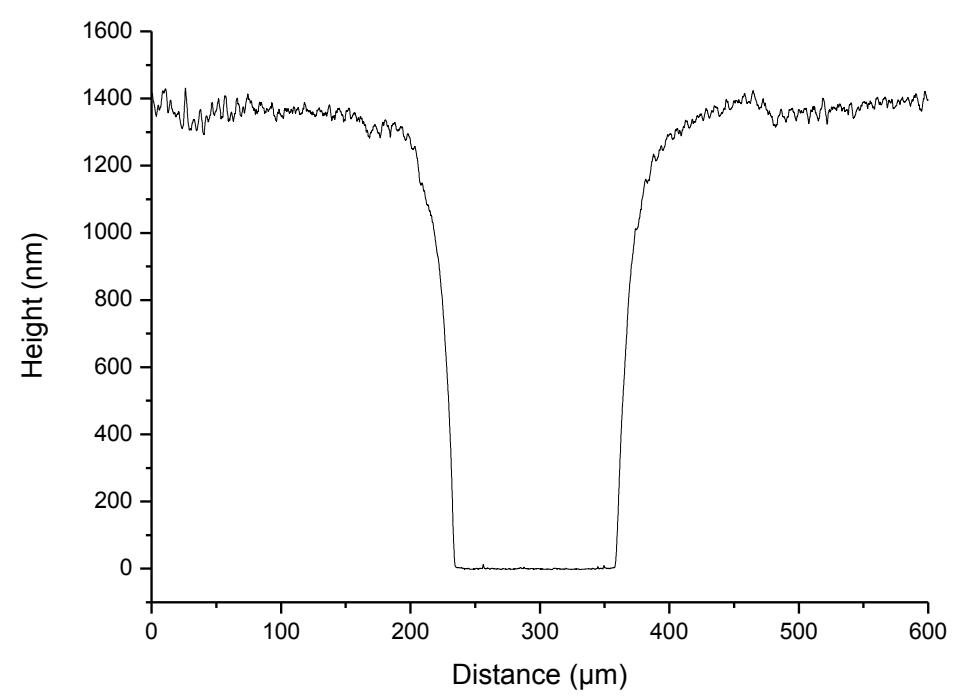

Figure S8. Height profile of photopatterned P1 film. The measurements were performed with a profilometer (Dektak 150, Bruker).
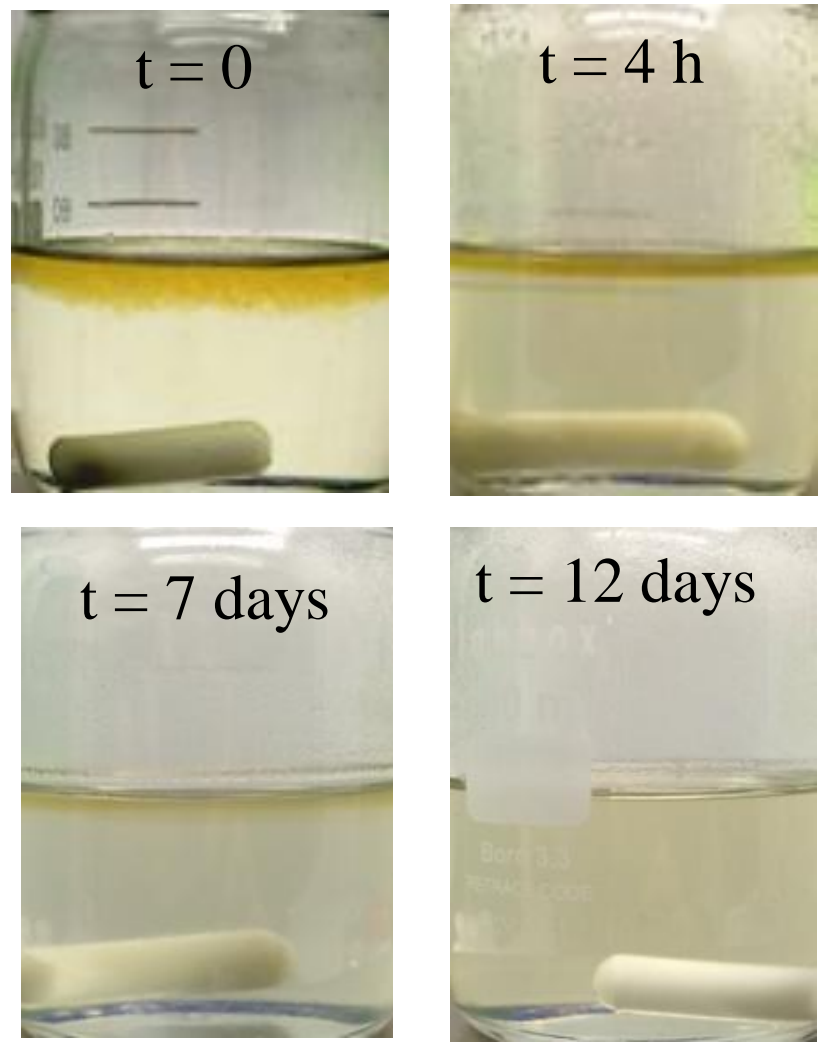

Figure S9. Pictures showing the reductive depolymerization of polymer P1. Reduction conditions: P1 with 8 eq of DTT and 0.75 eq of $\mathrm{EtN}_{3}$ under stirring. 

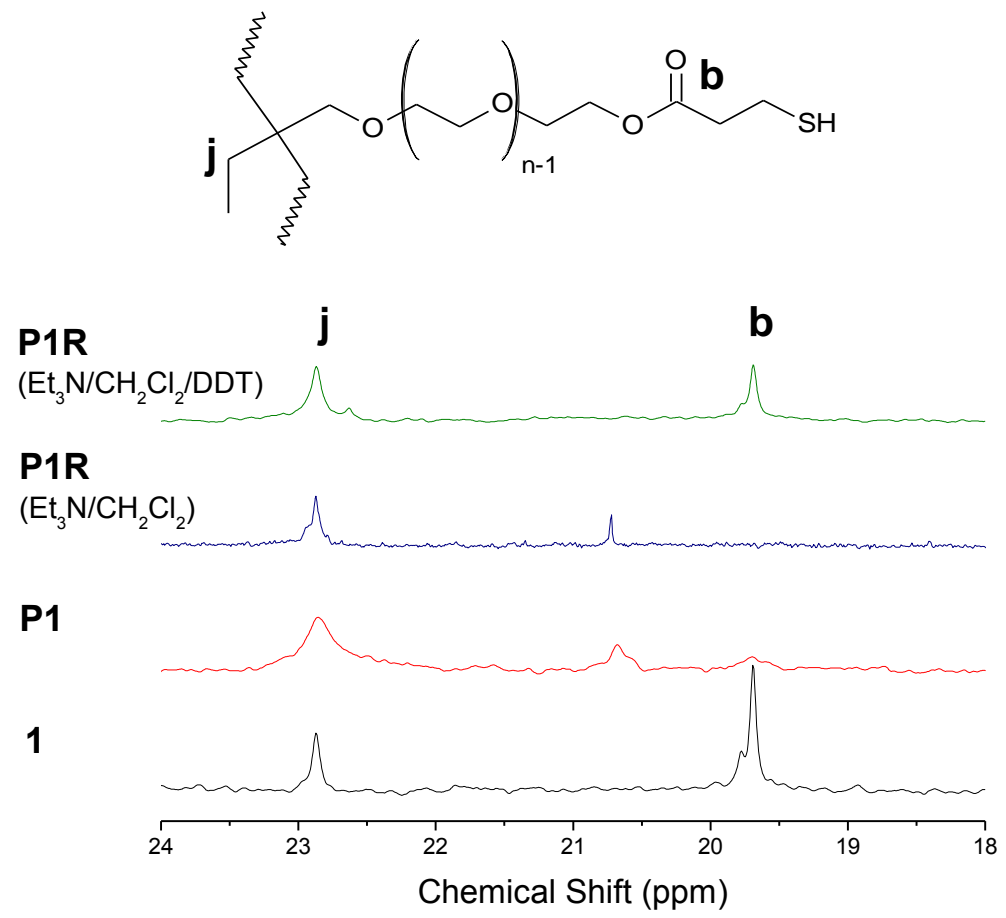

Figure S10. ${ }^{13} \mathrm{C}$ NMR spectra of thiol oligomer 1, poly(disulfide) P1, and the latter polymer after reduction P1R with or without dithiothreitol (DTT). 